
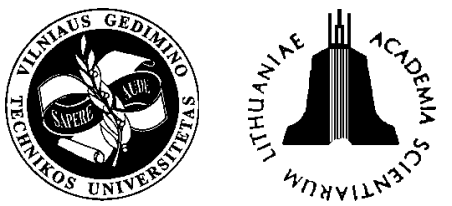

ISSN 1648-4142 TRANSPORT

http:/www.vtu.lt/english/editions

\title{
THE USAGE OF THE RAILROAD TERMINAL RESOURCES
}

\author{
Aldona Jarašūnienè \\ Transport Research Institute, Vilnius Gediminas Technical University, Plytinès g. 27, LT-10105 Vilnius, Lithuania. \\ E-mail: ajarasuniene@yahoo.com
}

Received 200312 22; accepted 20040401

\begin{abstract}
With the growth of freight transportation by rail the main attention should be focused on the function of railway terminal activities and optimization, where the arriving trains are disbanded and new trains are arranged according to the train formation plan A loading process is analyzed. Functional structure of terminals is defined by a technological process. The dynamic tasks of management of trains flows are formulated.

The efficiency of railway terminal activities should depend on the optimization of the process of growth of freight transportation.
\end{abstract}

Keywords: railroad terminal; reserves; number of loaders, operators; cargo fronts, which are operated by one team; optimization of activity.

\section{Introduction}

The process carried out with the cargoes in the railroad terminal consists of these operations: unloading of cargoes from the trucks, warehousing, storing, earthing and loading to the trucks. All these operations are done in the cargo front and cargo treatment is processed in the industrial sections. So this means that a lot of work is distributed to the loaders and operators of work zones. In every section, depending on the amount of work and the nature one or more teams might treat the amount of cargo. Brigade work can be specialized according to the clients, cargo fronts, the type of equipment etc. But there can be some universal teams. The process of the railroad cargo treatment demands to coordinate these two types of work organization. This type is called "mixed" and it is widespread.

Loaded or empty loads are operated by the closest vacant or the next one vacant team in the cargo front.

Special teams in the railroad terminal which cannot change each other, are operating in some cargo fronts. The combined way to carry out the work is mostly used. And the best way to organize the cargo unity storing and warehousing problems is to use special teams.

Cargo front researches in the railroad terminals showed that a loading process consists of a big amount of the different operation elements which responds to the external influence on the parameters and defines the incoming orders.

Every incoming order which needs to be treated consists of two parts: 1) cargoes with the characteristics to be transported. 2) types of transportation unity. These two parts have some links that describe the amount of work and the quantity of means of loads [1-4].

\section{Loading process functional structure in terminals is defined by a technological process}

This system is distributed into the organizational and functional parts. The description of the organizational parts structure shows how this system is made. And the structure of different kinds of each element depends on the type of description $[5,6]$.

There are four types of cargo front system elements: $T$ - reserves; $F$ - cargo front; $M$ - equipment; $s$ - area under warehouse.

Each type might be distributed into a big amount of different kinds of elements. So this means that a loading process structure is mixed in the terminal.

The purpose of the systematic description is to find out the characteristics and links of every element. It is necessary to distribute the systematic characteristics and links, which influence the most loading process in the terminal:

$T$ is a number of loaders, operators, cargo fronts, which are operated by one team and the time of every operating front evacuation and the schedule of the teamwork.

$F$ is cargo front mechanization, the type of every treated amount of the cargo, the number of means of transport operating at the same time and the time to treat one 
means of transport, a number of loaders for every means of transport, the output of each loader.

$M_{1}$ is a number of measures, a number of cargo fronts operated by one measure, a number of teams to serve one measure time to operate every cargo front.

$M_{2}$ is a number of loaders working by periods and operating one cargo front, a number of the operating fronts, a number of teams to operate one loader, time spent to treat every cargo front by the loader.

$M_{3}$ is time spent to operate the main line transport loads during 24 hours by stationary machinery.

$\sigma$ is a number of cargo front to store.

Links between $T, F, M$ show a loading system functional structure. Functional description reflects the processes, parameters and variability of the system. The organization of the loading process has connections with the other operation groups: to deliver means of transport to the cargo front; teams migration between cargo fronts; reconstructing and laying out of the machinery in the cargo front; operating the loading processes; loaders traffic in the cargo front; the schedule of the stationary loading machinery during 24 hours; teamwork schedule monthly.

A loading process functional structure in terminals is defined by the regular (lasting) technological links between the elements. It is called a technical process.

This process consists of a lot of operations connected to each other: the treatment of the means of transport from the cargo front to admit the transport, which has already done some operations.

Inherent links between the cargo fronts, teams, mobile equipment settles the redistribution of the resources, which ensures operating for every front. The outward links between the incoming system, single elements and out coming ones are defined by the loading process system interaction with the outward surroundings and changes of the system structure influenced by this interaction.

The influence of the outward surroundings is defined by the schedule, structure (loaded, empty trucks and wagons, their types and capacity) of the orders, cargo structure (cargo and package type, total amount of the cargo), technical demand of the orders.

In the main cases the purpose of the system research might be expressed by the time, spent by means of loads in the cargo front as the function:

$$
t_{f}=f\left(t_{1}, t_{2}, \ldots, t_{s}\right),
$$

$t_{1}, t_{2}, \ldots, t_{s}$ - time spent by every means of transport in the period of the system $1,2, \ldots, s$.

The functional estimating of the cargo front by every means of transport during the time period is substantiated as the main quantitative indicator, which shows the conditions of the treatment for the means of loads transport in this analyzed system. When we know $t_{j}$, we can find a lot of different kinds of indicators in a price level. All the cargo treatment elements and operations might be provided as a big amount, classified by the characteristic parameters. Every cargo front might be described as unique collection of the elements and the sequence of operations, which defines the technology of a loading process [7, 8].

The main things that influence the type of cargo front and structure are the types of used loading mechanisms. Following this feature all the cargo fronts are ascribed to one of four groups:

1) Cargo fronts, where people are doing the operations with cargoes without using machinery;

2) Cargo fronts with stationary loading equipment;

3) Cargo fronts operated by the mobile loading equipment (every mechanism has one or more fronts to operate);

4) Mixed service type in the cargo front (every front has one or more mechanisms, every loading mechanism has one or more fronts).

A loading process has a lot of restrictions at the terminal. Unconditional limits are: nominal staff work time period and the schedule of the mechanisms.

These restrictions can be operated and changed according to the demands of the system. They consist of: the schedule of the front work, front area, the preferences of the service, the quantity of staff etc.

The other restrictions are formal, for example, the same number of the provided amounts of the treated and not treated cargoes.

Now we will analyze the work reserves allotment and reallotment of the mechanisms optimization problem in railroads terminals when we use two types of the road transport: the main and the local lines of transport carrying the cargoes out of the terminal for a short distance.

Huge capacity of the main line rail transport $m(m=1, \ldots, M)$ comes into the terminal with different type of cargoes $n(n=1, \ldots, N)$. The main line rail transport is unloaded in various cargo fronts $j(j=1, \ldots, J)$, a lot of different unloading mechanisms $p(p=1, \ldots, P)$ are used for the unloading process. Unloaded cargoes are stored or reloaded from the huge capacity main line rail transport to loads $l(l=1, \ldots, L)$.

It is necessary to coordinate all the main line transport sent for unloading, loading equipment and road transport work that the unloading process out of the main line transport and taking the cargoes out would take as little time and resources as possible. To solve this problem we can use the dynamical problems solving method in the processes of transport.

The network of transport forms the modelling of the transport processes. It is the whole of the tops (points, 
junctions, warehouses, loading areas) and the edges (main lines, local lines).

The edges consist of the important indicators, real transport link characteristics: distance; trip time; permeability; migration price of mechanisms and people; expenditures of transportation and etc. Two possible directions of traffic conform with two edges missed each other. There are production, application points, warehouses, grounds, loading areas with the loading equipment at the tops of the network.

To define the capacities of the junctions it is necessary to avoid the problems bound with the treatment of the cargo and to build the right capacity warehouses.

If the amount of the stream (people, mechanisms, means of transport) is restricted to pass through the edges of the network, it means that the edges are of limited permeability. Due to this $G(V, E)$ is the transport network, $V=\{i\}$ - tops, $E\{i, j\}$-edges $(i ; j=1, \ldots, n)$. Dynamic problems are the problems of estimating the motion of the stream through the edges of the network $G(V, E)$. The tops have resources and the followings of cargoes with the known production and usage dynamics. The stream of the tops of the network $V$, can be stored for some period.

We will mark $(i, j)$ that the time $t_{i j}$ is the edge of passing and it is necessary for the unity of stream to go from the top $i$ to the top $j$. without decreasing generality and wishing to simplify the formulation of a problem we will say that all $t_{i j}$ are equal to 0 , or +1 , or -1 . Obviously every dynamic problem regarding this dynamic stream can be formulated in the way to satisfy this proposition. Let $V(t)$ be a dynamic lot of the tops with periods of time $t=1, \ldots, T$. In the case of dynamic possibility tops are marked by two indexes $(i, j) \in V(t), i-$ the number of the top, $i=1, \ldots, n(t)$ and $t$ - the period of time.

We will mark $E(t)$ as a dynamic lot of edges when there are passing and temporary edges between them, which initial tops are $(i, t) \in V(t)$. The passing edges are marked with tops of two indexes $\left((i, t),\left(i, t^{\prime}\right)\right) \in E(t)$, $t^{\prime}=T+1$. The tops of the waiting edges: $\left((i, t),\left(i, t^{\prime}\right)\right) \in E(t)$ and the time of waiting $t_{i i}=1$ and $t^{\prime}$ have just the only meaning $t+1$.

The edges having initial and final tops in the same interval are called local edges; edges which have initial top at time period $t$ and final top in interval $t+k$ are called connecting.

We will formulate the dynamic problem of transport: passing time $t_{i j}=0$, we will define the passing price $t_{i t j t} x_{i j t t}$ of stream $x_{i t j t}$ for the edges $(i, t),(j, t)$ and the storing price $C_{i t i t}{ }^{\prime} x_{i t i t}{ }^{\prime}$ of stream $x_{i t j t}{ }^{\prime}$ for the edges $\left((i, t),\left(i, t^{\prime}\right)\right)$. We will mark the offer $a_{i t}$ and demand $b_{j t}$ in the top $i$ at time $t$. Following a transport problem dynamic way will be:

$$
\begin{aligned}
& \min \left[\sum_{t=1}^{T} \sum_{(i t) \in V(t)} \sum_{(j t) \in V(t)} C_{i t j t} x_{i t j t}+\right. \\
& \left.\sum_{t=1}^{T} \sum_{(i t) \in V(t)} \sum_{\left(j t^{\prime}\right) \in V(t)} C_{i t j t^{\prime}} x_{i t j t}\right] . \\
& \sum_{(i t) \in V(t)} x_{i t j t}+x_{j t j t}-x_{j t j t}=b_{j t}, \quad(j t) \in V(t) ; \\
& t=1, \ldots, T . \\
& \sum_{(j t) \in V(t)} x_{i t j t}+x_{i t i t}-x_{i t i t^{\prime}}=a_{i t}, \quad(i t) \in V(t) ; \\
& t=1, \ldots, T . \\
& x_{i t j t} \geq 0, x_{i t i t} \geq 0,((i, t),(j, t)) \in E(t), \\
& ((i, t),(i, t)) \in E(t) .
\end{aligned}
$$

Formulating the dynamic problem we can see that analyzing in this case cargo providing has no decisive meaning except that it is the motion of the loading mechanisms equal to zero and estimates only storing time duration. This is the duration of loading equipment work. If the conditions of the storing are not estimated in the dynamic problem then:

$$
\sum_{(j t) \in V(t)} x_{i t j t}=a_{i t}, \quad(i t) \in V(t), \quad t=1, \ldots, T
$$

In this case the condition is:

$$
\sum_{t=1}^{T} \sum_{i} a_{i t}=\sum_{t=1}^{T} \sum_{j} b_{j t} \text {. }
$$

The modification of the transportation problem optimization is about the optimal usage of the resources and mechanisms.

Statistical data showed that arriving into the terminal accidental nature, it has the intensity $\lambda$ of the cars every hour. The time spent to operate the truck in the cargo front is shown like the standard distribution with these indicators: mathematical expectancy $\bar{t}_{0} \mathrm{~min}$, and the average square deviation $\sigma_{0} \min$.

It is necessary to define the idle time of the loads and the moments of the loading start.

We can find the arrival time intervals of every load to every storehouse which exceeds the rates of the truck operation time. Also we can find rush hour intervals and the loading teams from one to the other cargo front. Loading equipment is directed to the cargo fronts where trucks are loaded from the empty fronts.

To find the expedience of this relocation to abolish the idle time of trucks we will use this inequality: 


$$
\frac{C_{p}}{t_{p}+t_{d}}>\frac{C_{0}+C_{d}}{t_{0}-t_{f}}
$$

$C_{p} ; C_{0}-$ arrived and treated trucks idle time price. $C_{d}$ - expenditures influenced by the relocation of the trucks and the idle time of loading equipment and staff. $t_{p} ; t_{0}$ - time spent to operate the arrived and treated trucks, $t_{f}$ - practical time spent to operate the trucks from the cargo front until new truck arrives, $t_{d}$ - time spent to relocate the equipment and trucks.

If the inequality is right, it is necessary to suspend the treatment of the loading trucks and to relocate. If it is wrong - to finish the process and to relocate equipment after that.

The least practical time period of the treatment with the minimum priority when it is not expedient to suspend it is defined:

$$
t_{f}^{\min }=t_{0}-\frac{\left(C_{0}+C_{d}\right) \cdot\left(t_{p}+t_{d}\right)}{C_{p}} .
$$

We have two indicators of the prices: $C_{i j k t}-$ the teams benefit got in comparison with the absence; $S_{i j k t}$ - the price of the allotment; $j$ - object the team was moved from; $k$ - new object.

$S_{i j k t}$ - is distributed to the expenditures of the relocation $S_{i j k t}^{p}$, and the lost effect for the idle time of wagon $S_{i j k t}^{n}$ (if this wagon was in the front, the team was moved).

$$
S_{i j k t}=S_{i j k t}^{p}+S_{i j k t}^{n} .
$$

We will use some marks: $t_{p}^{b}$ - time spent by the team to move to the other front; $t_{a}$ - the idle time period start of the not operated means of transport in the cargo front, $t_{0}^{b}$ - time to get a team if there was no work off brigade and there was no reason to suspend the process and to relocate the team; $t_{p}^{0}$ - truck treatment start time.

$$
C_{i j k t}=C^{\Delta E_{a}}+C^{\Delta k_{a}}+C^{s}+C^{E_{a}}+C^{\Delta E_{M}},
$$

$C^{\Delta E_{a}}$ - the economy of the expenditures in the system: "road transport - cargo front - railway";

$C^{\Delta k_{a}}$ - investments (capital) economy to buy the loads; $C^{s}$ - the capital economy got for the shortening the storing terms; $C^{E_{a}}$ - the capital saved for the increased turnover of cargo; $C^{\Delta E_{M}-\text { saved exploitation }}$ expenditures for the loading equipment.

$$
C^{\Delta E_{a}}=365 e_{a v} \cdot \Delta T_{a},
$$

$e_{a v}$ - the price of one load usage hour; $\Delta T_{a}$ the reduction of load idle time during 24 hours because of the optimal usage of the resources to load it.

The reduction of the load idle time in cargo fronts is the lengthening of the time spent for the capital investments to gain loads.

$$
C^{\Delta k_{a}}=\frac{\Delta \sum A_{v}}{t_{p}} C_{a},
$$

$\Delta \sum A_{v}$ Saved up time during 24 hours by every load; $t_{p}$ - average work time duration in 24 hours; $C_{a}-$ load price, $\mathrm{Lt}$.

$$
C s=e s\left(t s^{\prime}-t s^{\prime \prime}\right),
$$

$e_{s}$ - expenditures to save one tone of cargo in 24 hours, $\mathrm{Lt} ; t_{s}^{\prime}, t_{s}^{\prime \prime}$ - storing time in existing conditions and suggested conditions by new technologies.

$$
C^{E a}=G t_{s} C_{t} D
$$

$g$ - average amount of carried out cargo, tones; $t_{s}-$ inequality-storing time between two terms; $C_{t}$ - price of one tone of cargo; $\Delta$-index of the capital investments efficiency, equal to $1 / t_{p}^{0} ; t_{p}^{0}-$ dividend time.

$$
C^{\Delta E_{M}}=365 e_{M} t_{p c} Z,
$$

$e_{M}$ - price of every loading equipment work hour, Lt; $t_{p c}$ - work period in 24 hours; $Z$ - the amount of work of mechanisms.

Analyzing the work of different terminals and the interaction between various types of transport we can see:

1. The principal measures to reduce the idle time periods for the means of transport during the loading operations must help to avoid the unequal cargo arrival to cargo fronts.

2. It is possible to increase the efficiency of reserves usage by a better organized transportation process. It means: getting right information on time, using computers and coordinating work inside the terminals and between them. To increase and to reach it we need to establish the coordinating centers $[9,10]$.

\section{Dynamic tasks of management trains flows}

Discrete managed object will be described in the network of dynamic flow in proportion to the respective parameters:

$$
\begin{aligned}
& X(t+1)=X(t)+B^{+} U(t)+B^{-} U(t+1), \\
& t=\overline{0, T-2} ; \\
& X(T)=X(T-1)+B^{+} U(T-1) ; \\
& X(0)=X^{0} ; \\
& l(t, \xi) \leq U(t) \leq f(t, \xi) ;
\end{aligned}
$$




$$
\begin{aligned}
& X(t) \leq g(t, \xi), \quad t=\overline{1, T} ; \\
& \left.\begin{array}{l}
0 \leq X(t) \\
0 \leq U(t)
\end{array}\right\}, \quad t=\overline{0, T} .
\end{aligned}
$$

Here we will present four most typical objectives of dynamic management of transport flows [11, 12].

1. The objective of maximum dynamic flow in the network. It is necessary to maximise the quantities of the flow delivered to the destination point per $T$ time moments. Formally the essence of the objective is that knowing the initial state (8) we chose such permissible management (9), (11) for the object $(6,7,10,11)$, which gives maximum meaning to the functional $J_{0}(X, U, t)$. In this issue the criterion is:

$$
X_{n}(T) \rightarrow \max .
$$

Initial conditions in this issue will be presumed in the following shape $X^{0}=(\infty, 0, \ldots, 0)$. Sometimes additional conditions are assumed that the whole flow going out from the peak 1 , will reach the destination peak $n$ at $T$ time periods. To fulfil this condition we shall presume $g(T)=\{\infty, 0, \ldots, 0, \infty\}$.

2. The objective of minimal cost. Let $R(t)$ be the cost vector of carrying a flow unit along the network panes at the time moment $t$. It is necessary to minimise the notion:

$$
\sum_{t=0}^{T=1}(R(t), U(t)) \rightarrow \min
$$

limitations being $(6,11)$.

Initial conditions have the shape:

$$
X^{0}=(x, 0, \ldots, 0),
$$

here $x$ - the extent of flow to be carried along the network $G$. In order that the whole flow could reach the peaks $n$, it is necessary that:

$$
g(T)=\{0,0, \ldots, 0, x\} .
$$

Without this precondition it may be stated that:

$$
g(T)=\left(0, \alpha_{2}, \alpha_{3}, \ldots, \alpha_{n}\right),
$$

when $0 \leq \alpha_{i} \leq x, \sum \alpha_{i}=x$.

3. Minimisation of the flow extent filling in the $d y$ namic set of panes. Let us select in the network $G$ the minimum extent dynamic flow from 1 to $n$ at $T$ intervals of time filling in the panes from $\Omega(t)$ and meeting the conditions (6)-(11). The criterion of the objective is as follows:

$$
X_{n}(T) \rightarrow \max ,
$$

whereas $l(t ; \xi)=f(t ; \xi)$ for all panes from the set $\Omega(t)$. Initial conditions are:

$$
X^{0}=(\infty, 0, \ldots, 0) \text { and }
$$

$$
g(T)=(\infty, 0, \ldots, 0, \infty) .
$$

According to the contents this issue is interpreted as an objective of the identification of a minimal number of transport means with the aim of ensuring the transport traffic according to the schedule, organising the carriage by all transport modes except pipeline transportation.

4. Maximisation of transportation profit. Let us presume the given flow extent $x$, which is at a time moment in 0 resource. For each pane we will introduce two extents:

$$
f_{e}^{1}(t, \xi), f_{e}^{1}(t, \xi), f_{e}^{2}(t, \xi)=f_{e}^{1}(t, \xi),+f_{e}^{2}(t, \xi) .
$$

Let us presume that the flow along the pane consists of two parts $U_{e}^{1}(t)$ and $U_{e}^{2}(t)$. To the flow $U^{1}(t)$ we shall relate the cost amount $\left.R(t), U^{1}(t)\right)$, to $U^{2}(t)$ - the profit amount $\left(C(t), U^{2}(t)\right)$ when traffic is going along the network panes.

It is necessary to make a dynamic flow of a given extent in the network $G$, maximising general transportation profit during $T$ time moments.

Criterion of the objective is:

$$
\begin{aligned}
& \sum_{t=0}^{T=1}\left[\left(C(t), U^{2}(t)\right)\left(R(t), U^{1}(t)\right)\right] \rightarrow \max , \\
& U^{1}(t)+U^{2}(t)=U(t) .
\end{aligned}
$$

Initial conditions are the same as of the second objective.

$$
\begin{aligned}
& 0 \leq U^{1}(t) \leq f^{1}(t, \xi) \\
& 0 \leq U^{2}(t) \leq f^{2}(t, \xi)
\end{aligned} \quad t=\overline{0, T-1} .
$$

The fourth objective is peculiar for the planning of freight transportation by the maritime transport. The profit is related to the freight transportation and the costs - to the transportation of ballast.

The stochastic management model obtained as a result of the theoretical research of railroad freight transport flows enables the determination of a great group of optimal rail freight flows management issues.

\section{Conclusions}

1. The principal measures to reduce the idle time periods for the means of transport during the loading operations must help to avoid the unequal cargo arrival to cargo fronts.

2. It is possible to increase the efficiency of reserves usage by a better organized transportation process. It means: getting right information on time, using computers and coordinating work inside the terminals and between them. To increase and to reach it we need to establish the coordinating centers. 
3. The stochastic management model obtained as a result of the theoretical research of railroad freight transport flows enables the determination of a great group of optimal rail freight flows management issues, such as the issues on maximum dynamic flows in the network which could allow to calculate maximum wagon rate in a line; the objective of minimum cost, defining the extent of transported flow filling in the dynamic set of the pane, the objective the essence of which is the determination of the minimum quantity of wagon allowing efficient scheduling of transport traffic.

\section{References}

1. Southworth Frank, Peterson, Bruce E. Intermodal and intermodal freight network modelling. Transportation Research, Part C 8, 2000, p. 147-166.

2. Warren Powell B., Tassio Carvalko. A Real-Time Optimisation of Containers and Flatcars for Intermodal Operations. Transportations Science, Vol 32, No 2, May 1988, p. 110-126.

3. Zhan F.-B., Noon Ch.-E. Shortest Path Algorithms: An Evaluation Using Real Road Networks. Transportation Science, Vol 32, No 1. February, 1988, p. 65-73.

4. Nuzzolo A., Russo F., Cristali, U. A Doubly Dynamic Schedule - Based Assignment Model for Transit Networks. Transportation Science, Vol 35, No 3, August, 2001, p. 268 285.
5. Baublys A. Introduction to the theory of transport system. (Transporto sistemos teorijos ivvadas). Vilnius: Technika, 1997. 298 p. (in Lithuanian).

6. Baublys A. Transport system: models of development and forecast (Transporto sistema: plètros prognozès ir modeliai). Vilnius: Technika, 2003. 208 p. (in Lithuaniain).

7. Grau B. Typical technological process of work by distribution station (Типовой технологический процесс работы сортировочной станции). Moscow: Transport, 1995. 50 p. (in Russian).

8. Sotnikov E. Elements of managing theory by system of quality (Элементы теории управления качеством системы). Minsk: Nauka i technika, 2001. 41 p. (in Russian).

9. David Gillen, Elva Chang, Dong Johnson. Productivily Benefits and cost efficiencies from Inteligent Transportation System Applications to Public Transit. Transportation research record, 1747, Paper No 01-3244, 2001. 89 p.

10. Casey R. F., Labell L N., Lo Vecchio J. A., On R. S., Royal J. W., Schwenk J. C., Moniz L., Carpenter E. S. Advanced Public Transportation systems: The State of the Art, Update 2000, FTA, Washington, D. C., and Research and Special Programs Administration, Cambridge, Mass., 1998. 99 p.

11. Jarašūnienė A. The optimization of transport flows crossing Lithuanian customs-houses. Transport, Vol XVII, No 1, Vilnius: Technika, 2002, p. 15-18.

12. Jarašūnienė A. Formulation of optimal international freight transport objective. Transport, Vol XVII, No 5, Vilnius: Technika, 2002, p. 201-204. 